\title{
Biosynthesis of Lysine in Rhodotorula glutinis: Role of Pipecolic Acid
}

\author{
By M. KURTZ AND J. K. BHATTACHARJEE \\ Department of Microbiology, Miami University, \\ Oxford, Ohio 45056, U.S.A.
}

(Received I8 June 1974; revised 26 August 1974)

\section{SUMMAR Y}

Glutamate- $\alpha$-ketoadipate transaminase, saccharopine reductase, and saccharopine dehydrogenase activities were demonstrated in extracts of Rhodotorula glutinis but $\alpha$-aminoadipate reductase activity could not be measured in whole cells or in extracts. Lysine auxotroph lysI grew in the presence of L-lysine or DL- $\alpha$ aminoadipate and incorporated radioactivity from DL- $\alpha$-amino- $\left[\mathrm{I}^{-14} \mathrm{C}\right]$ adipate into lysine during growth. Growing wild-type cells converted $\mathrm{L}-\left[\mathrm{U}-{ }^{14} \mathrm{C}\right] \mathrm{lysine}$ into $\alpha-$ amino- $\left[{ }^{14} \mathrm{C}\right]$ adipate, suggesting both biosynthetic and degradative roles for $\alpha$-aminoadipate. Lysine auxotrophs lysi, lys2 and lys 3 of $R$. glutinis, unlike lysine auxotrophs of Saccharomyces cerevisiae, satisfied their growth requirement with L-pipecolate. Moreover, extracts of wild-type $R$. glutinis catalysed the conversion of L-pipecolate to $\alpha$-aminoadipate- $\delta$-semialdehyde. These results suggest a biosynthetic role for L-pipecolate in $R$. glutinis but not in $S$. cerevisiae.

\section{INTRODUCTION}

The diaminopimelic acid pathway is utilized for the biosynthesis of lysine in bacteria (Gilvarg, I960; Vogel, 1964; Truffa-Bachi \& Cohen, 1968), whereas the homocitric- $\alpha-$ aminoadipic acid pathway is utilized for the biosynthesis of lysine in yeast and other higher fungi (Mitchell \& Houlahan, 1948; Strassman \& Ceci, 1966; Broquist, 1971). Genetic and biochemical studies in Neurospora crassa and Saccharomyces cerevisiae support the scheme of the latter pathway (Fig. I). We have reported accumulation of homocitric, homoaconitic and homoisocitric acids in a lysine auxotroph of Rhodotorula glutinis, an oxidative red yeast (Bhattacharjee \& Strassman, 1967a; Glass \& Bhattacharjee, I971). To confirm and extend the general scheme for the biosynthesis of lysine in fungi, we report here the enzymic activities following the $\alpha$-ketoadipic acid step as well as the metabolism of $\alpha$-aminoadipic acid to lysine and vice versa in $R$. glutinis. A biosynthetic role of pipecolic acid is indicated in $R$. glutinis but not in $S$. cerevisiae.

$\alpha$-Ketoglutarate + acetate $\longrightarrow$ Homocitric acid $\rightleftharpoons$ cis-Homoaconitic acid $\rightleftharpoons$ Homoisocitric acid $\longrightarrow$ Oxaloglutaric acid $\longrightarrow \alpha$-Ketoadipic acid $\rightleftharpoons \alpha$-Aminoadipic acid $\longrightarrow \alpha$-Aminoadipic- $\delta$-semialdehyde $\rightleftharpoons$ Saccharopine $\rightleftharpoons$ Lysine

Fig. I. Proposed steps for the biosynthesis of lysine in $R$. glutinis. 


\section{METHODS}

Organisms and growth conditions. Lysine auxotrophs lysI, lys2, lys3, and wild-type $R$. glutinis (Glass \& Bhattacharjee, 197I) as well as lysine tester-strains and wild-type S. cerevisiae (Biswas \& Bhattacharjee, 1974) were used. Stock cultures were maintained on a glucose-nutrient medium and were grown in minimal medium (Crocker \& Bhattacharjee, I973) supplemented with L-lysine, L-pipecolic acid, or DL- $\alpha$-aminoadipic acid as required. Cultures were shaken at $30{ }^{\circ} \mathrm{C}$ in Delong culture flasks. Growth was determined by the increase in turbidity $\left(E_{550}\right)$ using a Coleman Universal spectrophotometer (model I4, Coleman Instrument Corp., Maywood, Illinois, U.S.A.).

Preparation of extracts and assay of enzyme activities. Dialysed extracts, prepared as described by Sinha \& Bhattacharjee (1970), were used as the source of enzymes. Protein content was determined by the biuret reaction (Gornall, Bardawill \& David, 1949).

Glutamate- $\alpha$-ketoadipate transaminase activity was determined by the method of Piediscalzi, Fjellstedt \& Ogur (I968) following the conversion of DL- $\alpha$-amino- $\left[\mathrm{I}^{14} \mathrm{C}\right]$ adipic acid to $\alpha-\left[{ }^{14} \mathrm{C}\right]$ ketoadipic acid. Radioactive $\alpha$-aminoadipic acid was purified by chromatography on a column of Dowex-I-formate before use. Following incubation ( $90 \mathrm{~min}$ ), protein in the reaction mixture was precipitated, removed by centrifugation, and radioactive $\alpha$-ketoadipic acid was isolated by chromatography on a column $(\mathrm{I} \times 30 \mathrm{~cm})$ of Dowex-I-formate (Bhattacharjee \& Strassman, $1967 b$ ). To study the effect of lysine on the biosynthesis of this enzyme, cultures were grown in minimal medium as well as in medium supplemented with lysine (100 $\mu \mathrm{g} / \mathrm{ml})$. Extracts from appropriate cultures were tested for the glutamate- $\alpha$-ketoadipate transaminase activity.

$\alpha$-Aminoadipate reductase (EC. I.2.I.3I) activity is dependent on $\alpha$-aminoadipate, ATP, $\mathrm{Mg}^{2+}$ and NADPH. This activity was measured in extracts by the method of Sagisaka \& Shimura (1959), or in whole cells by the procedure of Jones \& Broquist (1965).

Saccharopine reductase (EC. I.5. I . IO) and saccharopine dehydrogenase (EC. I.5. I .7) activities were measured by following the reactions in the reverse direction according to the methods of Jones \& Broquist (1965) and Saunders \& Broquist (1966), respectively. The compositions of the reaction mixtures for the $\alpha$-aminoadipate reductase, saccharopine reductase and saccharopine dehydrogenase assays were the same as those described earlier (Sinha, Kurtz \& Bhattacharjee, r97I).

The ability of extracts to convert $L$-pipecolic acid to $\alpha$-aminoadipate- $\delta$-semialdehyde was determined by incubating L-pipecolate with dialysed extract and buffer at $30^{\circ} \mathrm{C}$ for $30 \mathrm{~min}$ (Rodwell, 197I). Following incubation, the reaction mixture was heated with $p$-dimethylaminobenzaldehyde and the formation of a coloured derivative was determined by measuring $E_{460}$ as in the $\alpha$-aminoadipate reductase assay.

Metabolism of $\mathrm{DL}-\alpha$-amino- $\left[I^{14} C\right]$ adipate and $\mathrm{L}-\left[U-{ }^{14} C\right]$ lysine. Lysine auxotroph lysI of $R$. glutinis was grown in $25 \mathrm{ml}$ minimal medium supplemented with $\alpha$-amino- $\left[\mathrm{I}-{ }^{14} \mathrm{C}\right]$ adipate $\left(500 \mu \mathrm{g} ; 4.7 \times 10^{6}\right.$ c.p.m.). After $72 \mathrm{~h}$ the culture supernate was examined for radioactivity, cells were harvested, washed, and hydrolysed in a sealed tube (Bhattacharjee \& Tucci, 1969). The acidic component was separated from basic/neutral component by chromatography using Dowex-I-formate. Basic/neutral component and carrier L-lysine were chromatographed on a column $(\mathrm{I} \times 30 \mathrm{~cm})$ of Dowex-50 (Moore \& Stein, I95I). Fractions were analysed for lysine by ninhydrin (Moore \& Stein, 1948) and for radioactivity using a tolueneethanol solvent system (Bhattacharjee \& Sinha, 1972).

Wild-type cells were grown for $72 \mathrm{~h}$ in $50 \mathrm{ml}$ minimal medium supplemented with $10 \mu \mathrm{Ci}$ of $\mathrm{L}_{-}\left[\mathrm{U}-{ }^{14} \mathrm{C}\right] \mathrm{lysine}$. Cells were removed and the culture supernate was lyophilized and chro- 


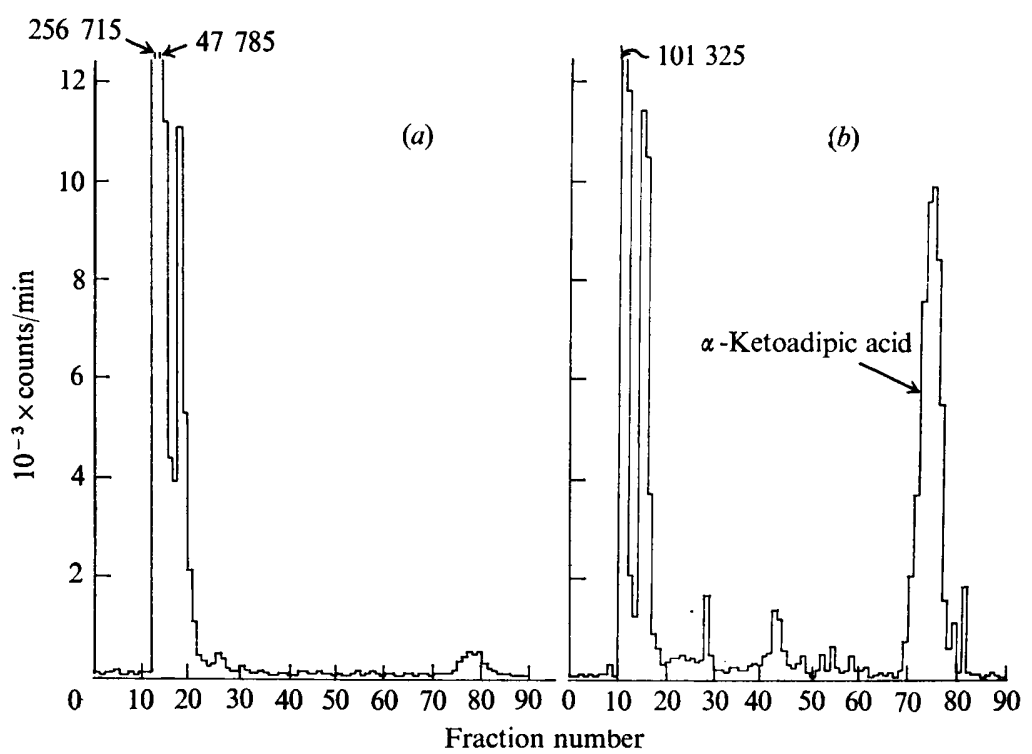

Fig. 2. Formation of $\alpha-\left[{ }^{14} \mathrm{C}\right]$ ketoadipic acid from DL- $\alpha$-amino-[ $\left[{ }^{14} \mathrm{C}\right]$ adipic acid $(a)$ using inactivated extract, or $(b)$ in a complete system with $R$. glutinis extract. Incubation mixture was chromatographed on a column $(\mathrm{I} \times 30 \mathrm{~cm})$ of Dowex-I-formate and eluted with continuous gradient to $6 \mathrm{~N}-$ formic acid. Individual fractions were analysed for radioactivity and the $\alpha$-ketoadipic acid peak (fractions 70 to 80 ) was identified by subsequent column and thin-layer chromatography.

matographed on a column $(\mathrm{I} \times 30 \mathrm{~cm})$ of Dowex-I-formate using a stepwise gradient of ammonium formate (Kuo, Saunders \& Broquist, 1964). Fractions containing labelled $\alpha$-aminoadipate were combined and further characterized by thin-layer chromatography.

Chemicals. Non-radioactive chemicals were from Sigma, and DL- $\alpha$-amino-[I- $\left.{ }^{14} \mathrm{C}\right]$ adipate and L-[U-14C]lysine were from Amersham/Searle, Chicago, Illinois, U.S.A.

\section{RESULTS}

\section{Enzyme activities}

Extract of wild-type $R$. glutinis exhibited significant glutamate- $\alpha$-ketoadipate transaminase activity (Fig. 2). No reaction was observed in the control experiment using heat-inactivated extract. A small satellite peak of radioactivity (fractions 17 to I9), in addition to the unreacted $\alpha$-aminoadipic acid peak (fractions I I to I5), was present in both profiles. The identity and significance of this split peak were not determined. Lysine in the growth medium reduced by $30 \%$ the ability of extract to form labelled $\alpha$-ketoadipate.

$\alpha$-Aminoadipate reductase activity was demonstrated both in whole cells and in extract of wild-type $S$. cerevisiae. However, wild-type $R$. glutinis failed to exhibit this enzyme activity in three different assay procedures (Table $I$ ). This enzyme activity also appeared to be absent in the lysI mutant of $R$. glutinis, although the growth of this mutant in the minimal medium was supported by $\alpha$-aminoadipate.

$\alpha$-Aminoadipate reductase activity in $S$. cerevisiae extract was stimulated $20 \%$ by the addition of lysine $(5 \mathrm{mg})$ and the activity was inhibited approximately $80 \%$ by higher amounts ( $15 \mathrm{mg}$ ) of lysine. Neither lysine nor excess $\alpha$-aminoadipate caused any restoration 
Table I. Summary of the enzyme activities for lysine biosynthesis in $R$. glutinis and $S$. cerevisiae

Organisms were grown at $30^{\circ} \mathrm{C}$, harvested and extracts prepared as described in the text. Conditions of assay and the reaction mixture (Sinha et al. 197I) for each enzyme were identical for $R$. glutinis and $S$. cerevisiae except for the source of enzyme.
$\alpha$-Aminoadipate reductase
Formation of $p$-dimethylaminobenzaldehyde adduct (increase in $E_{460}$ )
Formation of $o$-aminobenzaldehyde adduct by whole cells (increase in $E_{480}$ )
Oxidation of NADPH (decrease in $E_{340}$ )
Saccharopine reductase: formation of $p$-dimethyl- aminobenzaldehyde adduct (increase in $E_{460}$ )
Saccharopine dehydrogenase: oxidation of NADH (decrease in $E_{340}$ )
Pipecolate reductase: formation of $p$-dimethyl- aminobenzaldehyde adduct (increase in $E_{460}$ )

$\begin{array}{cc}R . \text { glutinis } & \text { S. cerevisiae } \\ 0.02(0.02) & \mathrm{I} .2(0.03) \\ 0.04(0.04) & 0.74(0.02) \\ 0.0(0.0)^{*} & 0.26(0.01) \\ 0.56(0.10) & \mathrm{ND} \\ 0.43(0.0) \dagger & \mathrm{ND} \\ 2 . \mathrm{I}(0.3) & 0.2(0.2)\end{array}$

ND, not determined.

Values in parentheses are control activities, obtained with heat-inactivated extract, except for: ${ }^{*}, \alpha-$ aminoadipate omitted; $\dagger$, lysine omitted.

Table 2. Metabolism of $\mathrm{DL}-\alpha$-amino- $\left[\mathrm{I}^{14} \mathrm{C}\right]$ adipic acid by the mutant strain lysI of $R$. glutinis

The mutant was grown in the presence of DL- $\alpha$-amino- $\left[\mathrm{I}^{14} \mathrm{C}\right]$ adipic acid. The cells were hydrolysed, and the acidic fraction was separated and the basic or neutral fraction was chromatographed with carrier lysine.

\begin{tabular}{|c|c|c|c|c|}
\hline \multirow[b]{2}{*}{$\begin{array}{l}\text { Starting } \\
\text { medium }\end{array}$} & \multirow[b]{2}{*}{$\begin{array}{l}\text { Culture } \\
\text { supernate }\end{array}$} & \multicolumn{3}{|c|}{ Cell-hydrolysate } \\
\hline & & $\begin{array}{l}\text { Acidic amino } \\
\text { acids }\end{array}$ & $\begin{array}{l}\text { Basic or neutral } \\
\text { amino acids }\end{array}$ & Lysine \\
\hline 4700 & 2380 & 32 & 1760 & 1617 \\
\hline
\end{tabular}

of this activity in $R$. glutinis extract. Change of $\mathrm{pH}(6 \cdot 5,7 \cdot 0$ and $8 \cdot 0)$, substitution of NADH for NADPH, or substitution of CTP, GTP, or UTP for ATP were also ineffective.

Saccharopine reductase and saccharopine dehydrogenase activities were present in $\boldsymbol{R}$. glutinis extract (Table I). Saccharopine reductase activity was confirmed spectrophotometrically by the saccharopine-dependent reduction of NADP. No activity was present in the control experiments, including the one with heat-inactivated extract. Saccharopine dehydrogenase activity was demonstrated by the lysine- and $\alpha$-ketoglutarate-dependent oxidation of NADH.

\section{Metabolism of $\mathrm{DL}-\alpha$-amino- $\left[\mathrm{I}-{ }^{14} C\right]$ adipate and $\mathrm{L}-\left[U-{ }^{14} C\right]$ lysine}

Culture supernate and the cell-hydrolysates of lysi of $R$. glutinis grown in the presence of DL- $\alpha$-amino- $\left[\mathrm{I}-{ }^{14} \mathrm{C}\right]$ adipate were analysed for radioactivity (Table 2 ). Radioactive material in the culture supernatant was identified chromatographically as $\alpha$-aminoadipate. Practically all the radioactivity in the basic/neutral portion of the cell-hydrolysate was eluted with the carrier lysine in the subsequent chromatographic analysis (Fig. 3). 


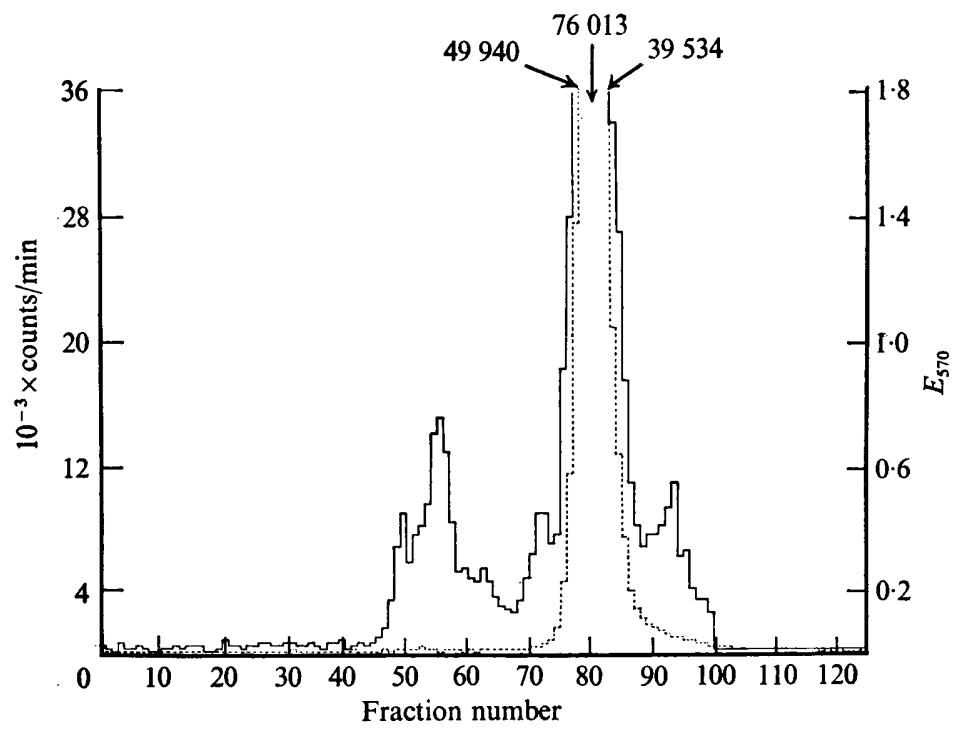

Fig. 3. Chromatographic profile of the basic/neutral component (amino acids) from lysi cells grown in the presence of $\mathrm{DL}-\alpha$-amino- $\left[\mathrm{I}-{ }^{14} \mathrm{C}\right]$ adipic acid. Hydrolysate was combined with carrier lysine and chromatographed on a column $(\mathrm{I} \times 30 \mathrm{~cm})$ of Dowex-50. Radioactivity (- - - ) of the individual fraction was determined by liquid scintillation spectrometry and the carrier lysine was determined by titration with ninhydrin $\left(E_{570} ;--\right)$.

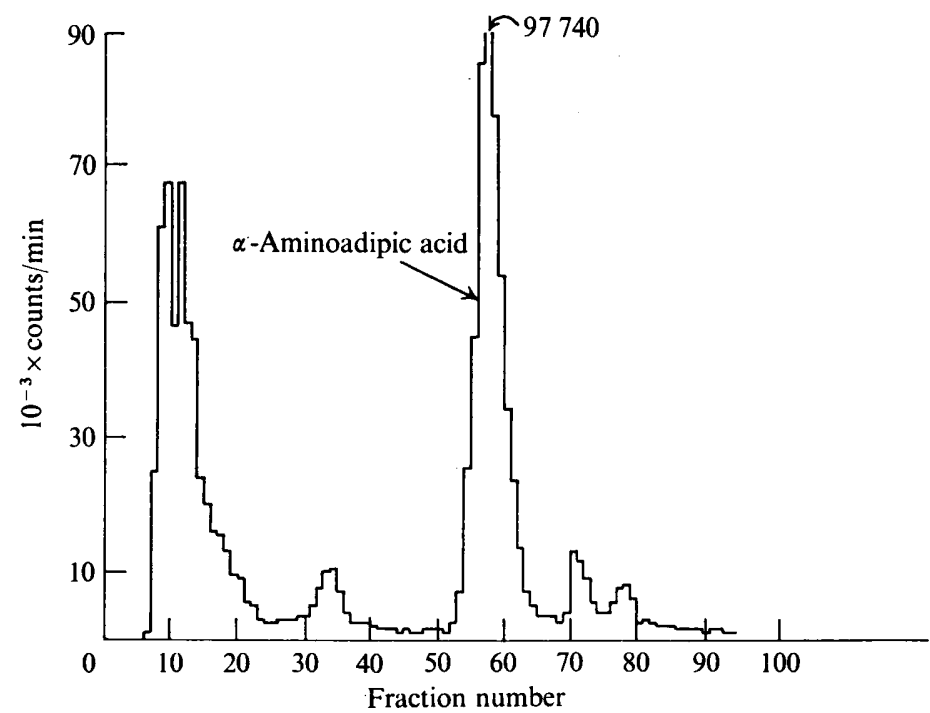

Fig. 4. Chromatographic profile of the culture supernate of wild-type $R$. glutinis grown in the presence of $\mathrm{L}_{-}\left[{ }^{14} \mathrm{C}\right]$ lysine. Culture supernate was chromatographed on a column $(\mathrm{I} \times 30 \mathrm{~cm})$ of Dowex-I-formate. The column was eluted by a stepwise gradient of ammonium formate in water (ammonium formate: $0.04,0.08,0.12$ and $2 \mathrm{M}$ ) and the individual fractions were analysed for radioactivity. 
Table 3. Identification by thin-layer chromatography of radioactive $\alpha$-aminoadipic acid as a product of catabolism of $\mathrm{L}-\left[U-{ }^{14} C\right]$ lysine in $R$. glutinis

Solvent system

Butan-I-ol-acetic acid-water $(4: 1: 1)$

Butan-I-ol-formic acid-water $(7: 3: 3)$

Propan-I-ol-ammonium hydroxide $(7: 3)$

Chloroform-methanol-ammonium hydroxide $(2: 2: 1)$

\begin{tabular}{|c|c|}
\hline \multicolumn{2}{|c|}{$\boldsymbol{R}_{\boldsymbol{F}}$ value } \\
\hline $\begin{array}{l}\alpha \text {-Aminoadipic } \\
\text { acid }\end{array}$ & $\begin{array}{l}\text { Radioactive } \\
\text { product }\end{array}$ \\
\hline $\begin{array}{l}0.08 \\
0.65\end{array}$ & $\begin{array}{l}0.08 \\
0.67\end{array}$ \\
\hline 0.35 & 0.35 \\
\hline 0.95 & 0.95 \\
\hline
\end{tabular}

Table 4. Growth response to L-pipecolic acid of lysine auxotrophs of $R$. glutinis

The turbidity $\left(E_{550}\right)$ was measured after $96 \mathrm{~h}$ growth at $30{ }^{\circ} \mathrm{C}$.

\begin{tabular}{|c|c|c|}
\hline Mutant & Addition to the minimal medium & $E_{550}$ \\
\hline lysi & $\begin{array}{l}\text { None } \\
\text { L-Lysine } \\
\alpha \text {-Aminoadipic acid } \\
\text { L-Pipecolic acid }\end{array}$ & $\begin{array}{l}0.29 \\
0.76 \\
0.43 \\
0.72\end{array}$ \\
\hline lys 2 & $\begin{array}{l}\text { None } \\
\text { L-Lysine } \\
\alpha \text {-Aminoadipic acid } \\
\text { L-Pipecolic acid }\end{array}$ & $\begin{array}{l}0.03 \\
0.75 \\
0.03 \\
0 \cdot 72\end{array}$ \\
\hline lys3 & $\begin{array}{l}\text { None } \\
\text { L-Lysine } \\
\alpha \text {-Aminoadipic acid } \\
\text { L-Pipecolic acid }\end{array}$ & $\begin{array}{l}0.03 \\
0.45 \\
0.03 \\
0.52\end{array}$ \\
\hline
\end{tabular}

Both labelled lysiné (fractions 8 to I5) and $\alpha$-aminoadipate (fractions 54 to 62 ) were present in the culture supernate of wild-type $R$. glutinis grown in the presence of L-[U- $\left.{ }^{14} \mathrm{C}\right] l y s i n e$ (Fig. 4). The radioactive material from the $\alpha$-aminoadipate peak was further characterized on thin-layer chromatography using known carrier (Table 3). One of the minor peaks (fractions 30 to 40 ) exhibited a similar elution profile to that of saccharopine.

\section{Role of pipecolic acid}

Nutritional studies on lysine auxotrophs were carried out by adding L-lysine, DL- $\alpha-$ aminoadipate, or L-pipecolate $(40 \mu \mathrm{g} / \mathrm{ml})$ to the minimal medium. $\alpha$-Aminoadipate supported the growth of lysI whereas L-pipecolate, like L-lysine, supported the growth of all three mutants, lysi, lys2, lys3, of $R$. glutinis (Table 4). L-Pipecolate failed to support the growth of any of the lysine auxotrophs of $S$. cerevisiae. Like wild-type $R$. glutinis, extracts of lys 2 and lys 3 (non-utilizer of DL- $\alpha$-aminoadipate) showed saccharopine dehydrogenase and saccharopine reductase activities but no $\alpha$-aminoadipate reductase activity. Extract of $R$. glutinis catalysed the formation of the $p$-dimethylaminobenzaldehyde adduct of $\alpha$-aminoadipate- $\delta$ semialdehyde from L-pipecolate (Table I). This activity remained unchanged with the addition of ATP or NADPH to the reaction system. Extract of $S$. cerevisiae was inactive for this reaction.

\section{DISCUSSION}

Crude extract of $\boldsymbol{R}$. glutinis exhibits glutamate- $\alpha$-ketoadipate transaminase, saccharopine reductase and saccharopine dehydrogenase activities. So far, attempts to demonstrate $\alpha$-aminoadipate reductase activity in $R$. glutinis with various conditions and assay methods remain unsuccessful. This lack of activity may be real or apparent. The enzyme may be 
particulate and inactivated during extraction, or the activity may require different co-factors or physiological conditions than the ones tested.

Metabolism of $\mathrm{DL}-\alpha$-amino-[ $\left.\mathrm{I}^{14} \mathrm{C}\right]$ adipate and $\mathrm{L}-\left[\mathrm{U}-{ }^{14} \mathrm{C}\right]$ lysine in growing $R$. glutinis, as well as the presence of saccharopine reductase and saccharopine dehydrogenase activities in wild-type and mutant strains, indicate that $\alpha$-aminoadipate functions as a biosynthetic precursor and a degradative product of lysine in this organism. Although $\alpha$-aminoadipate reductase is not demonstrable, it is believed that saccharopine reductase and saccharopine dehydrogenase function biosynthetically for the conversion of $\alpha$-aminoadipate to lysine and, as in man (Hutzler \& Dancis, 1968), catabolically in the conversion of lysine to $\alpha$-aminoadipate in this organism.

As is the case for the biosynthesis of lysine, there exists a considerable diversity of pathways for the catabolism of lysine. Several distinct catabolic routes for lysine have been proposed for different organisms (Rodwell, 1969). In Hansenula saturnus and Rhizoctonia leguminicola catabolism of lysine seems to involve acetylated intermediates (Rothstein, 1965; Guengerich \& Broquist, 1973). Catabolism of lysine in $N$. crassa and rat liver is believed to occur via lysine $\rightarrow \alpha$-keto- $\epsilon$-aminocaproate $\rightarrow \Delta^{\prime}$-piperidine-2-carboxylate $\rightarrow$ L-pipecolate (Rothstein \& Miller, 1954; Schweet, Holden \& Lowy, 1954). A biosynthetic role for pipecolate is indicated in the lysine pathway of Aspergillus nidulans (Aspen \& Meister, 1962) and Euglena gracilis (Rothstein \& Saffran, 1963). Based on the growth response of lysine auxotrophs to L-pipecolate and the ability of extract to convert L-pipecolate to p-dimethylaminobenzaldehyde adduct of $\alpha$-aminoadipate- $\delta$-semialdehyde, we believe that both $\alpha$-aminoadipate and L-pipecolate are biosynthetic precursors and convert via $\alpha$-aminoadipate- $\delta$-semialdehyde and saccharopine to lysine in $R$. glutinis (Fig. I). Mutants lysz and lys 3 are probably blocked in the $\alpha$-aminoadipate reductase step and thus fail to grow in the $\alpha$-aminoadipate-supplemented medium. We consider that the wild-type organism contains $\alpha$-aminoadipate reductase but that for some reason we cannot detect its activity in extracts.

Rhodotorula glutinis, like $A$. nidulans and $E$. gracilis, seems to utilize pipecolic acid for the biosynthesis of lysine but the precise mechanism remains to be elucidated. Present results do not rule out the conversion of L-pipecolate to lysine via the reverse reactions of lysine $\rightarrow \alpha$ keto- $\epsilon$-aminocaproate $\rightarrow \Delta^{\prime}$-piperidine-2-carboxylate $\rightarrow$ pipecolate. It can be stressed that pipecolate is not utilized for the biosynthesis of lysine in $S$. cerevisiae.

We thank Dr J. Hutzler, School of Medicine, New York University, for a generous gift of saccharopine, Dr A. K. Sinha for many helpful discussions and Dr R. J. Brady for reading the manuscript. This work was supported by NSF grant GB-28558X and grants from Eli Lilly and Co. and the Faculty Research Committee, Miami University.

\section{REFERENCES}

AsPen, A. J. \& Meister, A. (1962). Conversion of $\alpha$-aminoadipic acid to L-pipecolic acid by Aspergillus nidulans. Biochemistry I, 606-612.

BhattacharJeE, J. K. \& SinHa, A. K. (1972). Relationship among the genes, enzymes, and intermediates of the biosynthetic pathway of lysine in Saccharomyces. Molecular and General Genetics 115, 26-30.

Bhattacharjee, J. K. \& Strassman, M. (1967a). Accumulation of tricarboxylic acids related to lysine biosynthesis in a yeast mutant. Journal of Biological Chemistry 242, 2542-2546.

BhattacharjeE, J. K. \& Strassman, M. (1967 b). Accumulation of $\alpha$-ketoadipic acid by a lysine requiring yeast mutant. Journal of the Albert Einstein Medical Center 15, 44-49.

BhatTACHARJeE, J. K. \& TUCCI, A. F. (1969). Relationship of glutaric acid to the homocitric acid pathway of biosynthesis of lysine in yeast. Journal of Biological Chemistry 244, 1417-1423. 
BisWAS, G. D. \& BHATTACHARJEE, J. K. (1974). Inductions and complementation of lysine auxotrophs in Saccharomyces. Antonie van Leeuwenhoek 40, 22I-23I.

BroQuist, H. P. (1971). Lysine biosynthesis (yeast). In Methods in Enzymology, vol. 17B, pp. I12-129. Edited by S. P. Colowick and N. O. Kaplan. New York: Academic Press.

CROCKER, W. H. \& BHATtACHARJeE, J. K. (1973). Biosynthesis of glutamic acid in Saccharomyces: accumulation of tricarboxylic acid cycle intermediates in a glutamate auxotroph. Applied Microbiology 26, 303-308.

Gilvarg, C. (1960). Biosynthesis of diaminopimelic acid. Federation Proceeding 19, 948-952.

GLASS, J. \& BHATtACHARJEE, J. K. (1971). Biosynthesis of lysine in Rhodotorula: accumulation of homocitric, homoaconitic, and homoisocitric acids in a leaky mutant. Genetics 67, 365-376.

Gornall, A. G., Bardawill, C. J. \& David, M. M. (I949). Determination of serum protein by means of the biuret reaction. Journal of Biological Chemistry 177, 75I-766.

GUENGERICH, F. P. \& BroQuist, H. P. (1973). Lysine catabolism in yeasts and fungi. Federation Proceedings (Abstract) 32, 2 I 29.

Hutzler, J. \& Dancis, J. (1968). Conversion of lysine to saccharopine by human tissues. Biochimica et biophysica acta 158, 62-69.

JoNES, E. E. \& Broquist, H. P. (1965). Saccharopine, an intermediate of the aminoadipic acid pathway of lysine biosynthesis. Journal of Biological Chemistry 240, 253 I-2536.

Kuo, M. H., Saunders, P. P. \& Broquist, H. P. (1964). Lysine biosynthesis in yeast: a new metabolite of $\alpha$-aminoadipic acid. Journal of Biological Chemistry 239, 508-514.

Mitchell, H. K. \& Houlahan, M. B. (1948). An intermediate in the biosynthesis of lysine in Neurospora. Journal of Biological Chemistry 174, 883-887.

MOORE, S. \& STEIN, W. H. (1948). Photometric ninhydrin method for use in the chromatography of amino acids. Journal of Biological Chemistry 176, 367-388.

MOORE, S. \& STEIN, W. H. (195I). Chromatography of amino acids on sulfonated polystyrene resins. Journal of Biological Chemistry 192, 663-681.

Piediscalzi, N., FJellstedt, T. \& OgUR, M. (I968). A glutamic- $\alpha$-ketoadipic transaminase in Saccharomyces. Biochemical and Biophysical Research Communications 32, 380-384.

Rodwell, V. W. (1969). Carbon catabolism of amino acids. In Metabolic Pathways, vol. 3, pp. 19I-235. Edited by D. Greenberg. New York: Academic Press.

Rodwell, V. W. (1971). Pipecolic acid. In Methods in Enzymology, vol. 17B, pp. 174-188. Edited by S. P. Colowick and N. O. Kaplan. New York: Academic Press.

Rothstein, M. (1965). Intermediate of lysine dissimilation in the yeast, Hansenula saturnus. Archives of Biochemistry and Biophysics III, 467-476.

Rothstein, M. \& MilleR, L. L. (1954). Conversion of lysine to pipecolic acid in Rat. Journal of Biological Chemistry 211, 85I-858.

Rothstern, M. \& SAfFran, E. M. (1963). Lysine biosynthesis in algae. Archives of Biochemistry and Biophysics 101, 373-377.

Sagisaka, S. \& Shimura, K. (1959). Enzymatic reduction of $\alpha$-aminoadipic acid by yeast enzyme. Nature, London 184, I709-1710.

SAUNDERS, P. P. \& BRoQuist, H. P. (1966). Saccharopine, an intermediate of the aminoadipic acid pathway of lysine biosynthesis. IV. Saccharopine dehydrogenase. Journal of Biological Chemistry 24r, 3435-3440.

Schweet, R. S., Holden, J. T. \& Lowy, P. H. (1954). The metabolism of lysine in Neurospora. Journal of Biological Chemistry 211, 5I 7-529.

Sinha, A. K. \& Bhattacharjee, J. K. (1970). Control of a lysine biosynthetic step by two unlinked genes of Saccharomyces. Biochemical and Biophysical Research Communications 39, 1205-1210.

Sinha, A. K., Kurtz, M. \& Bhattacharjee, J. K. (197I). Effect of hydroxylysine on the biosynthesis of lysine in Saccharomyces. Journal of Bacteriology 108, 715-719.

Strassman, M. \& CeCI, L. N. (I966). Enzymatic formation of cis-homoaconitic acid, an intermediate in lysine biosynthesis in yeast. Journal of Biological Chemistry 24I, 5401-5407.

Truffa-BaChi, P. \& CoHEN, G. N. (1968). Some aspects of amino acid biosynthesis in microorganisms. Annual Review of Biochemistry 37, 79-108.

VoGeL, H. J. (1964). Distribution of lysine pathways among fungi: evolutionary implications. American Naturalist 98, 435-446. 